\title{
Vitamin and trace element administration during continuous renal replacement therapy (CRRT) in the Intensive Care Unit (ICU)
}

\author{
Thomas Datzmann* and Karl Träger \\ Department of Anesthesiology, University Hospital Ulm, Ulm, Germany
}

Administration of nutrients during critical illness is depicted in current guidelines, e.g. in the guidelines of the American Society for Parenteral and Enteral Nutrition (ASPEN) [1] or in the European Society for clinical Nutrition and Metabolism (ESPEN) [2]. Special recommendations for critically ill children requiring continuous renal replacement therapy (CRRT) also exist [3]. The prescription of micronutrients like vitamins and trace elements is of moderate evidence especially for renal dysfunction and during CRRT and solid data of adequate micronutrient administration during critical illness are lacking. The dynamic of critical illness should be kept in mind which can have a relevant impact for vitamin or trace element requirement.

Early initiation (within 24-48 hours) of continuous enteral nutrition is strongly recommended, common consensus, and without issues concerning the enteral administration of micronutrients. Usually, commercially available enteral feeding preparations contain micronutrients in contrast to commercially available parenteral solutions because of stability reasons [2]. Therefore, during parenteral nutrition a separate administration of vitamins and trace elements is necessary to prevent deficiency [2]. But measurements of micronutrient concentrations are not routinely performed in the daily clinical practice.

The administration of micronutrients is highly relevant during critical illness because of their key roles in cell signaling, metabolism, antioxidant defense, gene synthesis, and repair [2]. Therefore, micronutrients should be administered as essential nutrients to parenterally fed patients to prevent deficiency syndromes [4].

Loss of micronutrients is achieved in particular by convection during continuous venovenous hemofiltration $(\mathrm{CVVH})$, which can be combined with diffusion as continuous venovenous hemodiafiltration (CVVHDF). Thus, micronutrients are lost during CRRT because the molecular weight is below the cut-off point of the filters. But additionally other mechanisms like adsorption may lead to loss of micronutrients although no data are available in the current literature.

Critically ill patients needing CRRT have altered vitamin and trace element requirements and especially long-lasting CRRT (> two weeks) can cause relevant micronutrient deficiencies and may lead to lifethreatening complications when deficiencies are not balanced [2].

Only a few studies are available with respect to vitamin or trace element loss and corresponding administration during CRRT in the ICU.

Relevant loss of folate, cobalamin and thiamin during CRRT was observed in adult and pediatric patients [5-7]. But loss of folate and cobalamin was covered by the dietary reference intakes and not clinically relevant in adults [7]. Copper, selenium, and zinc loss was detected during CRRT and also covered by the provided daily dose of trace element prescription in children [6] and adults [5,7]. However, significant loss with negative balance of copper and selenium was observed in a study in eleven adult patients with multiple organ failures even if the daily recommended intake was administered [8]. Today, there is no strong evidence in the current literature regarding target levels of vitamins and trace elements which causes different conclusions in the above-mentioned studies. The prescription of micronutrients strongly depends on illness-related deficiencies as well as individual requirements.

Overall, data suggest that current nutritional recommendations cover the loss of micronutrients during CRRT, taking into account limited knowing about target levels.

Micronutrients with antioxidative properties (i.e. folate, selenium, and zinc) may improve patients' outcome in recommended doses and may have beneficial effects during massive oxidative stress (e.g. septic shock or trauma) $[9,10]$. But high dose administration of antioxidative micronutrients is only recommended for proven deficiencies in current ESPEN guidelines [2].

Major issues today are that micronutrient level measurements are not implemented in the daily clinical practice and that there is no solid data for disease and treatment-related administration.

These facts clearly suggest that micronutrient nutrition and corresponding measurements during CRRT should be considered individually to avoid a negative impact on patients' outcome. Overall, the doubled recommended daily intake of vitamins and trace elements should meet patients' needs during CRRT in the ICU without harm.

\section{References}

1. McClave SA, Taylor BE, Martindale RG, Warren MM, Johnson DR, et al. (2016) Guidelines for the Provision and assessment of nutrition support therapy in the adult critically ill patient: Society of Critical Care Medicine (SCCM) and American Society for Parenteral and Enteral Nutrition (A.S.P.E.N.). JPEN J Parenter Enteral Nutr 40: 159-211. [Crossref]

*Correspondence to: Thomas Datzmann, Department Anesthesiology, University Hospital Ulm, Albert-Einstein-Allee 23, 89081 Ulm, Germany, Tel: +49 731500 43061; Fax: +49 731500 43002; E-mail: thomas.datzmann@uni-ulm.de

Key words: nutrition, micronutrients, critical illness

Received: July 17, 2019; Accepted: August 02, 2019; Published: August 06, 2019 
2. Singer P, Blaser AR, Berger MM, Alhazzani W, Calder PC, et al. (2019) ESPEN guideline on clinical nutrition in the intensive care unit. Clin Nutr 38: 48-79.

3. Jonckheer J, Vergaelen K, Spapen H, Malbrain M, De Waele E (2019) Modification of nutrition therapy during continuous renal replacement therapy in critically ill pediatric patients: A narrative review and recommendations. Nutr Clin Pract 34: 37-47. [Crossref]

4. Biesalski HK, Bischoff SC, Boehles HJ, Muehlhoefer A (2009) Water, electrolytes, vitamins and trace elements - Guidelines on parenteral nutrition, chapter 7. German Medical Science 7: Doc21.

5. Churchwell MD, Pasko DA, Btaiche IF, Jain JC, Mueller BA (2007) Trace element removal during in vitro and in vivo continuous haemodialysis. NDT 22: 2970-2977.

6. Pasko DA, Churchwell MD, Btaiche IF, Jain JC, Mueller BA (2009) Continuous venovenous hemodiafiltration trace element clearance in pediatric patients: a case series. Pediatric Nephrology 24: 807-813.
7. Datzmann T, Trager K, Schroppel B, Reinelt H, von Freyberg P (2018) Treatment dose and the elimination rates of electrolytes, vitamins, and trace elements during continuous veno-venous hemodialysis (CVVHD). Int Urol Nephrol 50: 1143-1149.

8. Berger MM, Shenkin A, Revelly JP, Roberts E, Cayeux MC, et al. (2004) Copper selenium, zinc, and thiamine balances during continuous venovenous hemodiafiltration in critically ill patients. Am J Clin Nutr 80: 410-416. [Crossref]

9. Mertens K, Lowes DA, Webster NR, Talib J, Hall L, et al. (2015) Low zinc and selenium concentrations in sepsis are associated with oxidative damage and inflammation. $\mathrm{Br} J$ Anaesth 114: 990-999. [Crossref]

10. Manzanares W, Dhaliwal R, Jiang X, Murch L, Heyland DK (2012) Antioxidant micronutrients in the critically ill: a systematic review and meta-analysis. Crit Care 16: R66. [Crossref]

Copyright: $@ 2019$ Datzmann T. This is an open-access article distributed under the terms of the Creative Commons Attribution License, which permits unrestricted use, distribution, and reproduction in any medium, provided the original author and source are credited. 